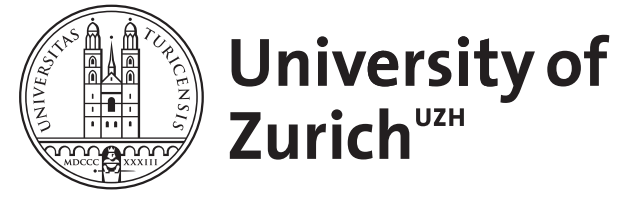

\title{
An analysis of non-response in a Swiss national survey
}

Dey, Michelle ; Mohler-Kuo, Meichun

DOI: https://doi.org/10.1007/s00038-012-0377-6

Posted at the Zurich Open Repository and Archive, University of Zurich ZORA URL: https://doi.org/10.5167/uzh-65505

Journal Article

Published Version

Originally published at:

Dey, Michelle; Mohler-Kuo, Meichun (2013). An analysis of non-response in a Swiss national survey. International Journal of Public Health, 58(2):323-326.

DOI: https://doi.org/10.1007/s00038-012-0377-6 


\title{
An analysis of non-response in a Swiss national survey
}

\author{
Michelle Dey $•$ Meichun Mohler-Kuo
}

Received: 17 February 2012/Revised: 24 May 2012 / Accepted: 1 June 2012/Published online: 20 July 2012

(c) Swiss School of Public Health 2012

Keywords Response rate · Non-participation · Mixed method · Survey

\section{Introduction}

Survey response rates generally have been decreasing over the recent decades (Curtin et al. 2005; Dillman et al. 2009; Galea and Tracy 2007; Morton et al. 2006). For example, response rates for the annual U.S. National Health Interview Survey declined from $80.4 \%$ in 1997 to $72.5 \%$ in 2004 and $60.8 \%$ in 2010 (http://www.cdc.gov/nchs/ nhis/quest_data_related_1997_forward.htm). The reasons for this increasing rate of non-participation could be summarized as an overwhelming number of requests for study participation, a general decrease in volunteerism, distrust in science, and increasing complexity of studies that require lengthy consent forms or involve complicated procedures (Galea and Tracy 2007 for review).

One major concern associated with non-participation is non-response bias, which refers to systematic errors in data that occur in a study when the reasons for (non-)participation are somehow linked to the main outcomes of interest (Asch et al. 1997; Curtin et al. 2005; Dillman 1991; Galea and Tracy 2007). Researchers have tried numerous different ways to enhance response rates in attempts to minimize non-response bias and increase the representativeness of study samples. One such means is to utilize a variety of survey data collection methods within a single study

M. Dey $(\bowtie) \cdot$ M. Mohler-Kuo Institute of Social and Preventive Medicine, University of Zurich, Hirschengraben 84, 8001 Zurich, Switzerland

e-mail: michelle.dey@uzh.ch
(Dillman et al. 2009; Galea and Tracy 2007). With a mixed methods approach, otherwise eligible individuals who fail to respond to one survey method (e.g., telephone interviews) are subsequently given the opportunity to respond via another (e.g., written questionnaires). However, problems with mixed method designs may arise when responses differ as a function of the survey method selected (Dillman et al. 2009; Galea and Tracy 2007).

Consequently, the main aims of the present study were (1) to assess whether response rates vary by survey method (telephone vs. mail); (2) to evaluate whether the main outcome (in our case, the prevalence of children with special health care needs; CSHCN) is influenced by survey method; and (3) to identify reasons for non-participation.

\section{Methods}

The "National Survey of Children with Special Health Care Needs in Switzerland" (approved by the Ethics Committee of the University of Zurich) used a national representative sample of 16,496 children, ages 9-14 years, drawn from a canton/municipality-based population (Mohler-Kuo et al. 2011). The main goal of the survey was to estimate the nationally prevalence of children with special health care needs using the "CSHCN Screener" with parents as proxy respondents (Bethell et al. 2002). The survey primarily was conducted by computer-assisted telephone interviews. However, for those parents whose telephone numbers could not be found $(2,859)$ or who could not be reached by telephone $(1,340)$, a written screening questionnaire and information letter were sent by mail. On the written questionnaire, the parents were asked to provide their telephone number. If they did, they were contacted again by telephone. If the parents did not return 
the questionnaire within approximately 1 month, a reminder and second questionnaire were sent. Telephone interviews and questionnaires were available in all three official Swiss languages (German, French and Italian). The reason(s) parents refused to participate could only be assessed among those parents who were contacted by telephone. Multiple answers were permitted.

\section{Results}

Altogether, 10,830 parents (or other caretakers) responded to the survey (9,371 by telephone interview; 1,044 by written questionnaire; 415 by written questionnaire and telephone interview). The overall response rate was $65.7 \%$. For those parents whose telephone number was found and who were reached $(12,297)$, the response rate was $76.2 \%(9,371 / 12,297)$. For those parents to whom the written questionnaires were sent (parents whose telephone numbers were not found initially $(2,859)$ and those parents whose telephone numbers were found but were unable to be reached $(1,340))$, the response rate was $34.4 \%(1,459 /$ $4,199)$. Hence, those parents who were contacted by mail were more likely not to participate in the survey $(\mathrm{OR}=6.0(5.6-6.5))$. Furthermore, parents of non-Swiss children were more likely not to participate in the survey relative to parents of Swiss children (non-participation rates: $46.2 \%$ vs. $22.8 \%$; OR $=2.9(2.6-3.2))$. Due to the high association between the mode of data collection (telephone vs. written) and nationality (contacted by telephone: Swiss parents $=79.2 \%$ vs. non-Swiss parents $=$ $57.6 \% ; \chi_{1}^{2}=409.043 ; p<0.001$ ), we included both factors in a logistic regression model to adjust for potential confounding. In this model, both factors remained significantly associated with non-participation. However, the adjusted odds ratio for non-participation declined to 3.6 (3.2-4.1) for those parents to whom the questionnaires were sent and to $2.4(2.1-2.7)$ for the parents of non-Swiss children.

Besides looking at response rates, we also assessed whether actual responses varied as a function of survey mode and found that the prevalence of CSHCN did not differ between those who responded by telephone and those who responded by mail $\left(13.9 \%\right.$ vs. $13.2 \% ; \chi_{1}^{2}=0.388$; $p=0.534)$.

We further examined the reasons for non-participation among 1,800 parents who actively refused to participate, among whom $79.6 \%$ provided their reason(s) for nonparticipation (Table 1). The most frequently mentioned reasons for non-participation were "did not want to provide information about their children" (23.5\%) and "lack of interest in the study topic" $(16.2 \%)$. We further examined the reasons for non-participation by nationality. Significant differences in reasons for non-participation were identified between parents of Swiss and non-Swiss children. For example, versus parents of non-Swiss children, significantly more parents of Swiss children mentioned (1) "did not believe that data protection was ensured" $(8.1 \%$ vs. $1.6 \%)$ and (2) "lacked trust in the study/research" (6.1\% vs. $1.6 \%)$ as their reasons for non-participation. On the other hand, significantly more parents of non-Swiss children mentioned: "lack of interest in the study topic" $(23.6 \%$ vs. $15.6 \%)$ and "were concerned that the interview would be overheard by the telephone institute supervisor" (1.6\% vs. $0.3 \%)$ as their reasons for nonparticipation.

\section{Discussion}

Our response rate $(65.7 \%)$ was similar to that of other Swiss national surveys (e.g., Swiss Health Survey; BFS 2008) and to that of U.S. surveys that have used the same instrument (Bethell et al. 2008). The response rate was much lower among those parents who were contacted by mail than those contacted by telephone. However, the results should be interpreted with caution, because parents were not randomly assigned to the mail versus telephone survey. It is possible that those parents whose telephone numbers could not be found in the public directory were more protective of their privacy and, therefore, less likely to participate in the survey. However, other studies also have identified higher response rates with telephone interviews than mailed surveys (e.g., Wettergren et al. 2011). Furthermore, more telephone numbers were found among parents of Swiss children than among parents of non-Swiss children. It is possible that more non-Swiss families choose not to list their telephone number in the public directories or that they just have mobile telephone numbers.

The finding that the response rate was higher among the parents of Swiss than non-Swiss children could be attributable to language/comprehension problems. Furthermore, one of the frequently mentioned reasons for non-participation among parents of non-Swiss children was their lack of interest in the study topic that could be partially attributed to language/comprehension problems, because they might not completely understand the invitation letter that we sent them to introduce the study.

The finding that the prevalence of $\mathrm{CSHCN}$ did not differ by data collection mode is indicative of the usefulness of mixed survey methods: such an approach could be justified to increase participation in a study to assess CSHCN without introducing bias secondary to data collection method.

Lastly, it was demonstrated that a common theme percolating through several of the main refusal reasons was 
Table 1 Reasons for non-participation in the National Survey of Children with Special Health Care Needs in Switzerland (conducted in 2010/2011)

\begin{tabular}{|c|c|c|c|c|}
\hline & $\begin{array}{l}\text { Total sample } \\
(N=1,800)\end{array}$ & $\begin{array}{l}\text { Parents of Swiss } \\
\text { children }(N=768)\end{array}$ & $\begin{array}{l}\text { Parents of non-Swiss } \\
\text { children }(N=123)\end{array}$ & $\chi_{1}^{2}$ \\
\hline Did not want to provide information about their children & $23.5 \%$ & $22.0 \%$ & $25.2 \%$ & 623 \\
\hline Lack of interest in the study topic & $16.2 \%$ & $15.6 \%$ & $23.6 \%$ & $4.814^{*}$ \\
\hline No time & $8.0 \%$ & $9.8 \%$ & $12.2 \%$ & 689 \\
\hline Felt overwhelmed by telephone inquires & $7.3 \%$ & $6.5 \%$ & $7.3 \%$ & 112 \\
\hline Felt that the topic was too personal & $6.7 \%$ & $6.5 \%$ & $8.9 \%$ & 984 \\
\hline Did not believe that data protection was ensured & $6.6 \%$ & $8.1 \%$ & $1.6 \%$ & $6.609 * *$ \\
\hline Lacked trust in the study/research & $5.2 \%$ & $6.1 \%$ & $1.6 \%$ & $4.120 *$ \\
\hline Personal issues & $1.5 \%$ & $1.3 \%$ & $0.8 \%$ & 208 \\
\hline Did not want to provide information over the telephone & $1.3 \%$ & $0.8 \%$ & $2.4 \%$ & 2.914 \\
\hline $\begin{array}{l}\text { Did not want to participate in any kind of survey as a matter } \\
\text { of principal }\end{array}$ & $0.7 \%$ & $0.8 \%$ & $0 \%$ & 967 \\
\hline $\begin{array}{l}\text { Were concerned that the interview would be overheard by the } \\
\text { telephone institute supervisor }\end{array}$ & $0.4 \%$ & $0.3 \%$ & $1.6 \%$ & $4.424 *$ \\
\hline Considered the interview too long & $0.1 \%$ & $0 \%$ & $0 \%$ & - \\
\hline Other reason(s) & $11.8 \%$ & $10.8 \%$ & $9.8 \%$ & 123 \\
\hline
\end{tabular}

Reasons for non-participation given by refusing parents reached by telephone (multiple answers permitted). Of the total 1,800 refusing parents, $1,433(79.6 \%)$ provided reasons for their non-participation. Information on nationality was not available for all children; therefore, the $N s$ of parents of Swiss or non-Swiss children do not add up to 1,800

$* p<0.05 ; * * p<0.01$

distrust in science ("did not want to provide information about their children", "did not believe that data protection was ensured", "lacked trust in the study/research", "did not want to provide information over the telephone", "were concerned that the interview would be overheard by the telephone institute supervisor"). Despite our efforts to address the trust issue, such as giving detailed information about the study and assuring all potential-participants about data protection, the problems remained. Other common reasons for non-participation included: (a) a lack of interest in the study topic (e.g., parents did not feel it was important to participate in the study when their child was healthy); (b) time constraints ("no time", "considered the interview too long"); (c) a rising number of study requests prompting a general refusal of all surveys ("felt overwhelmed by telephone inquires", "did not want to participate in any kind of survey as a matter of principal"); and (d) personal issues ("felt that the topic was too personal", "personal issues").

\section{Conclusions}

The present study demonstrates that a mixed survey methodology approach - combining telephone interviews and mailed written questionnaires - can be used to increase participation in surveys without influencing study outcomes. To enhance survey participation rates in the future, it will be especially important to increase the general population's overall trust in science (e.g., by advocating public information campaigns to increase science knowledge, and providing more detailed study introductions including how data will be handled to ensure data protection). In particular, greater efforts must be made to encourage and motivate parents of foreign nationalities to participate in studies (e.g., by providing additional language options to reduce non-participation secondary to comprehension difficulties).

Acknowledgments The authors are grateful to Prof. Dr. Guy Bodenmann for his extensive input on evaluating the reasons for study non-participation, and to Laurent Marti for his valuable input as well. This work has been supported by the Swiss National Science Foundation (325130_125486) and the Swiss School of Public Health.

Conflict of interest The authors declare that they have no conflicts of interest.

\section{References}

Asch DA, Jedrziewski MK, Christakis NA (1997) Response rates to mail surveys published in medical journals. J Clin Epidemiol 50:1129-1136

Bethell CD, Read D, Stein REK, Blumberg SJ, Wells N, Newacheck PW (2002) Identifying children with special health care needs: 
development and evaluation of a short screening instrument. Ambul Pediatr 2:38-48

Bethell CD, Read D, Blumberg SJ, Newacheck PW (2008) What is the prevalence of children with special health care needs? Toward an understanding of variations in findings and methods across three national surveys. Matern Child Health J 12:1-14

Bundesamt für Statistik (BFS) (2008) Erste Ergebnisse der schweizerischen Gesundheitsbefragung 2007, Neuchâtel, BFS

Curtin R, Presser S, Singer E (2005) Changes in telephone survey nonresponse over the past quarter century. Public Opin Q 69:87-98

Dillman DA (1991) The design and administration of mail surveys. Annu Rev Sociol 17:225-249

Dillman DA, Phelps G, Tortora R, Swift K, Kohrell J, Berck J, Messer BL (2009) Response rate and measurement differences in mixed- mode surveys using mail, telephone, interactive voice response (IVR) and the internet. Soc Sci Res 38:3-20

Galea S, Tracy M (2007) Participation rates in epidemiological studies. Ann Epidemiol 17:643-653

Mohler-Kuo M, Jann B, Dey M, Zellweger U (2011) A recruitment method to obtain community samples of children for survey research in Switzerland. Int J Public Health 56:353-356

Morton LM, Cahill J, Hartge P (2006) Reporting participation in epidemiologic studies: a survey of practice. Am J Epidemiol 163:197-203

Wettergren L, Mattsson E, von Essen L (2011) Mode of administration only has a small effect on data quality and self-reported health status and emotional distress among Swedish adolescents and young adults. J Clin Nurs 20:1568-1577 